\title{
Biblioteca Parque de Manguinhos: afetos, resistências e políticas no cenário cultural carioca. ${ }^{1}$
}

\author{
Biblioteca Parque de Manguinhos: afectos, resistencia y políticas en el \\ escenario cultural carioca
}

\author{
Library Manguinhos Park: affections, resistances and policies in the \\ carioca cultural scene
}

Esp. Karen Kristien Silva dos Santos ${ }^{2}$

\begin{abstract}
Resumo
Situada no Complexo de Manguinhos, um conjunto composto por 09 favelas e um dos polos de cultura do subúrbio do Rio de Janeiro, a Biblioteca Parque de Manguinhos (BPM), batizada como Biblioteca Marielle Franco, é fruto de um conjunto de políticas públicas voltadas para combate à violência em espaços periféricos. A biblioteca é integrante de uma rede composta por outras 04 unidades, 03 instaladas no município do Rio de Janeiro e uma em Niterói, através de parcerias entre as esferas de governo cujo formato foi inspirado no modelo adotado pelas cidades de Medellín e Bogotá na Colômbia (2006). A BPM figurou como centro de cultura, composto por teatro, cinema, ludoteca, midiateca e salas de leitura; e tornou-se referência no que se trata de oferta e fruição cultural na região onde foi implementada. Também recepcionou diferentes iniciativas ligadas a esporte, lazer, artes e educação oriundas do poder público, do terceiro setor e da sociedade civil. Entretanto, ao longo de sua existência, as bibliotecas parque foram vítimas da descontinuidade que assola os programas culturais no Rio de Janeiro. Em dezembro de 2016 as bibliotecas encerraram suas atividades pela inexistência de verbas para sua manutenção. Foram reabertas em 2018 após disputas pela gestão dos espaços entre o poder público e a iniciativa privada. Este relato debate este percurso histórico a partir da vivência de uma agente cultural formada na Biblioteca Parque de Manguinhos que acompanha a trajetória deste espaço que faz parte de suas relações pessoais e profissionais. $\mathrm{O}$ trabalho aborda a função social das bibliotecas públicas relacionado ao acesso à informação e cultura, e propõe a discussão a respeito do desenho de políticas públicas para territórios populares, suas interrupções e os impactos de políticas que deveriam ser de estado, porém são configuradas enquanto políticas de governo.
\end{abstract}

Palavras-Chave: Biblioteca Parque de Manguinhos; Favela; Políticas Culturais; Rio de Janeiro.

\section{Resumen}

Ubicada en Manguinhos, um conjunto compuesto por 9 favelas y uno de los polos de cultura del subúrbio de Rio de Janeiro el Parque Biblioteca de Manguinhos (BPM), bautizada como Biblioteca Marielle Franco, es fruto de un conjunto de políticas públicas orientadas hacia combate a la violencia en espacios periféricos. La biblioteca es integrante de una red compuesta por otras 04 unidades, 03 instaladas en Rio de Janeiro y una en Niterói, a través de alianzas entre las esferas de gobierno cuyo formato fue inspirado en el modelo adoptado por las ciudades de Medellín y Bogotá en Colombia (2006). La BPM figura como centro de cultura, compuesto por teatro, cine, ludoteca, mediateca y salas de lectura; y se hizo referencia en lo que se trata de oferta y de fructificación cultural en la región donde fue implementada. Recibió también diferentes iniciativas ligadas al deporte, el ocio, las artes y la educación procedentes del poder público, del tercer sector y de la sociedad civil. Sin embargo, a lo largo de su existencia, las bibliotecas parque fueron víctimas de la descontinuidade que asola a

\footnotetext{
${ }^{1}$ Artigo apresentado no Simpósio Temático 04 -Políticas públicas, diversidade cultural e descolonização durante o II Seminário Latino-Americano de Estudos em Cultura - SEMLACult em Foz do Iguaçu/PR, Brasil, 2018.

2 Especialista em Políticas Culturais de Base Comunitária; Faculdade Latinoamericana de Ciências Sociais FLACSO; Rio de Janeiro, RJ - Brasil; karenkristien@gmail.com
} 
los programas culturales en Rio de Janeiro. En diciembre de 2016 las bibliotecas cerraron sus actividades por la inexistencia de fondos para su mantenimiento. Se reabrieron en 2018 tras disputas por la gestión de los espacios entre el poder público y la iniciativa privada. Este relato debate este recorrido histórico a partir de la vivencia de una agente cultural formada en el Parque Biblioteca de Manguinhos que acompaña la trayectoria de este espacio que forma parte de sus relaciones personales y profesionales. El trabajo aborda la función social de las bibliotecas públicas relacionadas al acceso a la información y la cultura, y propone la discusión acerca del diseño de políticas públicas para territorios populares, sus interrupciones y los impactos de políticas que deberían ser de estado, pero se configuran como políticas de gobierno.

Palavras-clave: Favela; Parque Biblioteca de Manguinhos; Políticas Culturales; Rio De Janeiro.

\begin{abstract}
Situated at Manguinhos, a union of 9 favelas and part of the cultural center of Rio de Janeiro suburbia, Manguinhos' Park Library (MPL), baptized as Marielle Francos's Library, is the result of public policies that aims to fight violence in peripheries. MPL is an integrant part of a network composed of 4 other unities, 3 of which are at Rio de Janeiro and one in Niteroi, throughout partnerships between governmental spheres, which were inspired by models adopted by the cities of Medelín and Bogotá-Colombia (2006). The library became a cultural center composed by a theater, cinema, toy library, multimedia library and reading rooms; and became reference in the matter of cultural offer and recreation in the region where it was implemented. Also, it was home for initiatives of the public sector, the third sector and civil society in areas like sports, recreation and education. Unfortunately, throughout its existence, the park libraries were victims of the discontinuity which are part of cultural programs in Rio de Janeiro. In December of 2016, the libraries ceased to exist due to lack of funding for its maintenance. They were reopened in 2018 after disputes over the management of the libraries between the private and public sector. This report discusses this historical journey from the experience of a cultural agent formed in Manguinhos' Park Library, that accompanies the trajectory of this space that is part of her personal and professional relationship. This paper addresses the social function of public libraries related with access to information and culture, and it proposes a discussion in regards to the design of public policies towards public libraries, their interruption and the impact of policies which should come from the state but are configured as govern policies.
\end{abstract}

Keywords: Cultural Policies; Favela; Manguinhos’ Park Library; Rio De Janeiro.

\title{
1. Introdução
}

Manguinhos é um bairro localizado na zona norte da região metropolitana do estado Rio de Janeiro e também dá nome ao Complexo de Manguinhos, conjunto de 09 favelas. $\mathrm{O}$ próprio nome faz alusão a existência de áreas de manguezal, mas atualmente pouco preserva destas características devido a aterramentos e obras de urbanização realizadas na área. A região tornou-se famosa nos telejornais e na mídia impressa da cidade por seus baixos índices de desenvolvimento humano e altos índices de violência. O local foi um antigo distrito industrial, também abrigou empresas públicas e privadas além de unidades militares do Exército Brasileiro. Marcado pelo esvaziamento das indústrias, que mudaram de endereço, foi vítima de ações de remoções, obras urbanísticas, processos de regulação fundiária e ocupações populares. Nota-se que sua constituição territorial é fruto de disputas e tensões entre o crime organizado, a sociedade civil e o poder público.

No fim do ano de 2006 o governo federal iniciou uma série de intervenções na região com o intuito de ampliar o espaço urbanizado e prover melhores condições de vida para os 
moradores. Anteriormente foram realizadas obras pontuais, entretanto dessa vez a alternativa proposta para transformar esse cenário foi a implementação de um conjunto de equipamentos públicos para atender as demandas da população. Dentre os equipamentos implementados para atender a população, o espaço cultural ofertado foi a Biblioteca Parque de Manguinhos, cujas obras iniciaram em 2009 e foi inaugurada em abril de 2010.

\section{Contextualização: programas, políticas e inspirações}

O Programa de Aceleração do Crescimento (PAC) reuniu a esfera federal, estadual e municipal, para modificação de algumas áreas do bairro e estabelecimento de um pacote de serviços públicos para atender demandas por habitação, educação e saúde. Através da reforma de espaços e da reinstalação de moradores por meio de estratégias tais como compra assistida, indenização e aluguel social, foram realizadas obras de saneamento, construção de creches e conjuntos habitacionais. Os antigos galpões do quartel passaram a abrigar estabelecimentos de atendimento social, tais como a Biblioteca Parque de Manguinhos, a Unidade de Pronto Atendimento (UPA), a Clínica de Saúde da Família Victor Valla, o Centro de Referência da Juventude (CRJ), a Casa da Mulher de Manguinhos, o Centro de Apoio Jurídico (CAJ), o Núcleo de Geração de Trabalho e Renda, a Escola Estadual Compositor Luiz Carlos da Vila a primeira escola de ensino médio da região e o Centro Esportivo-Aquático localizado no interior da escola.

A proposta do PAC objetivava promover o crescimento sustentável e acelerado do espaço urbano, implantado em diferentes estados brasileiros seu enfoque era voltado para regiões marginalizadas. A efetivação do programa em Manguinhos possibilitou a chegada de políticas públicas de diferentes naturezas, como forma de atender não só necessidades básicas dos moradores, mas de modo a garantir o atendimento aos direitos culturais de acesso à arte, cultura e informação a população local.

Nesse cenário surge a Biblioteca Parque de Manguinhos enquanto equipamento cultural destinado ao público da região e inspirado na experiência da Biblioteca Parque España, situada em San Domingo, uma das partes mais violentas de Medellín na Colômbia. A ideia era prover espaços de cidadania em regiões vulneráveis e reunir uma biblioteca, um centro comunitário e um centro cultural no mesmo espaço. Logo, além do acervo de livros foram pensadas salas destinadas a reuniões e encontros, um cine-teatro, uma ludoteca, aulas de dança e gastronomia, acervos de audiovisual e games para os usuários.

\subsection{Bibliotecas Públicas e equipamentos culturais}


No Rio de Janeiro, assim como em outras capitais brasileiras, é visível a concentração de equipamentos culturais na área metropolitana do Centro e da Zona Sul. Nesses espaços geográficos está localizada uma parcela reduzida da população, uma parte da sociedade cujo poder aquisitivo é maior se comparado a moradores da Baixada Fluminense, Zona Norte e Oeste da cidade. Ou seja, aqueles que possuem maior renda têm acesso facilitado aos equipamentos e atividades, seja pelo aspecto financeiro ou pela mobilidade, enquanto, moradores de regiões suburbanas e distanciadas do eixo Centro-Zona Sul possuem um menor número de equipamentos culturais disponíveis, menos recursos financeiros para dispor a atividades de lazer, entretenimento e fruição cultural e menor possibilidade de deslocamento, dado que os trens, metrôs e ônibus não circulam de forma constante e regular.

Uma forma de contrapor a inexistência de equipamentos de cultura em regiões de favela e comunidades é a valorização do espaço público como lugar de sociabilidade. Logo, a construção de praças, parques, jardins, áreas de lazer em comunidade e espaços de favela é fundamental para prover a população o direito.

É válido ressaltar que no âmbito municipal há 09 bibliotecas públicas e 03 espaços de leitura, concentrados geograficamente e nenhum presente em espaço de favela. 05 encontramse nas regiões do eixo Centro-Zona Sul ,polos aglutinadores de teatros, cinemas e das poucas livrarias de rua da cidade. Nas demais regiões da cidade é possível encontrar lojas de vendas de livros em centros comerciais que em sua maioria não promovem atividades de incentivo ao livro e leitura voltados para públicos não consumidores.

O conceito das Bibliotecas Parque (BP) privilegia a cidadania e fortalece a parceria entre educação e cultura para apoiar o desenvolvimento de trajetórias juvenis em áreas de vulnerabilidade. Para tanto, suas atividades são pensadas como em parque: teatro, cinema, dança circo, comunicação, música. No discurso de seus gestores é possível entender que o papel das BPs é a promoção da palavra a partir de diferentes plataformas, contrapondo-se ao silêncio exigido nos locais tradicionais de leitura, onde o barulho é um incômodo e a experiência literária muita das vezes é individual. Pelo caráter de promover multilinguagens e estimular a vivência literária a partir de múltiplas práticas leitoras as BPs figuram como centros culturais nos locais onde estão instaladas.

A própria estrutura física da BPM privilegia diferentes áreas tais como o salão de leitura, salas para reuniões comunitárias, televisões para exibição de vídeos e $D V D$ s, cômodos com almofadas e mobiliário destinado ao conforto e relaxamento, mesas de computadores. Até mesmo a arquitetura é pensada para privilegiar novas formas de linguagem mediadas pela tecnologia. A construção da Biblioteca Parque em Manguinhos foi projetada em um cenário 
de praça arborizada e acompanhada de brinquedos e espaços de sombra, pensada para que seus usuários fruíssem não só do espaço interno e do acervo disponível, mas também do entorno enquanto lugar de interação com a natureza, integração social e destinado a práticas culturais. O que pode ser notado quando movimentos juvenis ocupam seus arredores mesmo após o encerramento de seu funcionamento. É possível observar jovens praticando batalhas de rima e poesia, andando de skate, ensaiando coreografias. Aos poucos a biblioteca tornou-se um ponto de encontro e um local de intercâmbio de vivências, o que reforçava sua natureza pública e democrática para além da concepção tradicional de bibliotecas.

\subsection{Instalação da Unidade Pacificadora de Polícia (UPP)}

No final de 2008 o estado do Rio de Janeiro iniciou a implementação de um novo programa de segurança pública e combate a violência urbana. A política de pacificação, segundo a Secretaria de Segurança Pública, foi desenhada a partir do conceito de polícia de proximidade, onde a parceria com a comunidade local é fundamental para viabilizar ações. Sobretudo para inaugurar a presença do Estado em territórios dominados pelo tráfico de drogas e milícias, através da oferta de atendimento a necessidades ligadas a infraestrutura e garantia de direitos sociais, tais como energia elétrica, água, coleta de lixo, escolas. De modo igual estimula a chegada de novos projetos socioculturais e provê oportunidades de emprego e renda a população. Em janeiro de 2013 foi instalada a UPP de Manguinhos, responsável pelo policiamento e segurança de aproximadamente 35 mil habitantes ${ }^{3}$ do Complexo. A unidade, em funcionamento até os dias atuais ${ }^{4}$, abrange as comunidades locais e indiretamente os bairros de Benfica, Bonsucesso, Jacaré e Maria da Graça. ${ }^{5}$

A chegada do programa ao bairro modificou substancialmente as dinâmicas sociais da região, uma vez que o momento inicial de chegada e fixação do policiamento no território foi cercado por embates com o poder paralelo, o que se desdobrou em incursões e operações com uso de armas de fogo, circulação de veículos de combate e o uso da autoridade policial para apreensão de drogas, armamentos e retomadas de endereços antes ocupados por marginais.

No início o programa obteve boas avaliações da população, porém com o seu avançar e a entrada em novos territórios nota-se uma inversão dessas expectativas positivas e

\footnotetext{
${ }^{3}$ Fonte: IBGE, Censo de 2010.
}

${ }^{3}$ A unidade de polícia pacificadora permanece em Manguinhos até o presente mês de julho de 2018.

${ }^{5}$ Fonte: UPP RJ. 
aprovação. A redução da criminalidade não se mostrou efetiva, mas sim momentânea, e as promessas de chegada de serviços públicos não foram cumpridas, tais fatores auxiliaram diretamente na mudança de avaliação do programa. Outro ponto relevante para reprovação do mesmo foi o abuso de autoridade e excessos cometidos por policiais que violaram os direitos humanos, como foi o caso observado na invasão de domicílios. As novas regras sociais determinadas pelas UPPs restringiam a circulação e permanência em espaços comuns a partir de horários pré-determinados e proibiam a realização de festas e eventos musicais (bailes funk, sambas e rodas de hip-hop) somaram a este cenário de desarranjos entre a realidade imposta pela chegada das UPPs e as dinâmicas das favelas e comunidades.

\subsection{O cenário pós "pacificação"}

As narrativas midiáticas produzidas sobre a pacificação transitavam entre a transmissão simultânea das disputas entre bandidos e polícia a exaltação das iniciativas de cultura e esporte existentes nos territórios. Até então muitos desses bairros e localidades eram reconhecidos a partir de estereótipos construídos por veículos jornalísticos e reforçados através da opinião pública. Como era o caso de Manguinhos, famoso por ser a "Faixa de Gaza" carioca devido a presença de marginais e moradores em situação de rua que ocupavam a linha do trem e a principal avenida do bairro.

As reportagens produzidas após as ocupações policiais de Manguinhos exaltavam as ações sociais e a Biblioteca Parque também foi matéria dos veículos jornalísticos. Contudo, as informações publicizadas atrelaram a existência da BPM ao processo de pacificação, mostrando-a como produto do processo, seja ocultando sua presença anterior ou reforçando a pacificação nos discursos relacionados à mesma.

\subsection{Interrupções: os impasses do poder público e o fechamento das Bibliotecas-Parque}

Na ocasião de sua inauguração em 2010 a gestão das BP era de responsabilidade do governo do Estado, na figura da Secretaria de Cultura (Sec) sob a gerência da superintendência de Leitura e Conhecimento. A administração do espaço, o gerenciamento de pessoal e supervisão de recursos coube à própria $\mathrm{Sec}$ e seus gestores públicos. Posteriormente o papel de gerência foi transmitido a uma organização social.

Em junho de 2015, após 05 anos de abertura, o governo anunciou a redução nos horários e dias de abertura das bibliotecas. A má gestão por parte do poder público, as mudanças de gestores tanto locais a frente das unidades, quanto nas cadeiras da Sec, somados 
a crise econômica que assolou o Rio de Janeiro comprometeu os convênios. O resultado foi o corte de verbas, a demissão de funcionários e alteração dos horários de atendimento para metade do expediente de abertura. Houve redução de dias de funcionamento, suspendendo as atividades aos finais de semana e impactando diretamente usuários e as ações culturais desenvolvidas nas unidades.

Até este momento as BPs estavam sob gestão do Instituto de Desenvolvimento e Gestão (IDG), organização social que recebia repasses do governo do Estado e que por ocasião do atraso das verbas atrasou o pagamento a terceirizados e fornecedores. $\mathrm{O}$ movimento Abre Biblioteca Rio, formado por profissionais e usuários da biblioteca, realizou uma série de protestos que resultaram em um pequeno aumento de horário de abertura e a garantia dos sábados na agenda dos espaços. O que proporcionou uma sobrevida até o mês de novembro, quando ainda por conta dos atrasos de repasse mais de 150 funcionários foram obrigados a assinar aviso prévio de demissão. Logo após esse episódio foi anunciado o fechamento das bibliotecas.

Em resposta a esta situação, a prefeitura do Rio de Janeiro declarou que assumiria a gestão das unidades de Manguinhos, Rocinha e do Alemão com uma verba muitíssimo inferior ao disponibilizado pelo governo do estado, e a unidade de Niterói foi arrendada pela prefeitura local.

Em setembro de 2016 a então secretária de cultura, Eva Doris, anunciou a previsão de abertura de dez novas unidades na Baixada e no interior do estado até 2018 a partir de parcerias público-privadas. Entretanto, em novembro a $\mathrm{SeC}$ foi mudada de pasta e em 29 de dezembro de 2016 as bibliotecas fecharam suas portas.

\subsection{A ocupação da BPM}

Mobilizados pelo encerramento das atividades, produtores culturais, coletivos locais, ex-funcionários e o público pleitearam a ocupação do espaço para atividades de teatro e dança e em 31 de janeiro de 2017 a BPM foi parcialmente reaberta. A secretaria concedeu o uso da parte externa e liberou o uso da entrada principal do prédio para ensaio de grupos artísticos.

A comunidade reunida realizou um mutirão de limpeza para que o espaço pudesse ser utilizado novamente e expôs a situação de deterioração do acervo e da parte interna da BPM. A ocupação, liderada pelo projeto social Ballet Manguinhos reuniu os agentes culturais para iniciar a gestão compartilhada e pressionar o poder público a respeito do acesso ao acervo bibliográfico. 


\subsection{Em 2018: a reabertura das bibliotecas}

A reinauguração da biblioteca aconteceu no dia 29 de março de 2018, que reabriu suas portas sob o nome de Biblioteca Marielle Franco em homenagem a vereadora vítima de um homicídio, que ao longo de sua trajetória lutou em defesa dos direitos humanos e residiu no Complexo da Maré, um bairro periférico da zona norte do Rio de Janeiro.

A unidade de Manguinhos foi a segunda a ser reaberta, anteriormente a unidade da Rocinha foi reinaugurada. O governo do estado assumiu a administração de forma direta, deslocando a equipe de servidores que estavam lotados na sede da SEC para atendimento ao público. A administração pública se comprometeu de contratar uma empresa privada para gerir os serviços, porém até hoje, julho de 2018, esta contratação não foi efetuada.

\section{Comparações, desafios e considerações finais}

Ao longo do relato é possível notar que apesar da inspiração inicial e da aspiração do espaço das BPs remontar características da experiência de Medellín, a iniciativa carioca necessita de conexão com a Colômbia em muitos aspectos. O desenho das políticas de forma simultânea é uma marca de instalação da unidade da biblioteca de Manguinhos, contudo não se deu de forma integrada. Questões como a mobilidade e o incentivo ao acesso ao espaço não foram trabalhados de forma estruturada.

O ponto que mais destaco é a ausência de participação social nas decisões ligadas a BPM. Nem os moradores, a equipe técnica ou mesmo os usuários foram consultados a respeito do destino e da forma com que a mesma seria gerida pelo Estado. Logo é compreensível que o sentimento de pertencimento não tenha alcançado um número maior de pessoas. A falta de mobilização comunitária não é reflexo da inexistência de protagonistas locais, mas da condução do espaço de forma burocratizada e desconectada de seus leitores e frequentadores.

O setor cultural no Rio de Janeiro é vítima do desmonte público: a redução de recursos e pessoal, a ausência de verbas de fomento e financiamento, o fechamento de espaços compõe o cenário atual. A gestão pública se mantém em silêncio e não esboça sinais de melhorias relativas a este quadro. $\mathrm{O}$ desenho de políticas não privilegiam o livro e leitura, mas ameaçam os avanços obtidos, visto que o exercício da cidadania cultural dos cariocas não está assegurado.

No caso das Bibliotecas Parque, as unidades do Alemão e do Centro do Rio permanecem de portas fechadas. A de Manguinhos e a da Rocinha não funcionam em sua capacidade total: há poucos funcionários disponíveis, parte das salas e dos salões de leitura 
estão fechados, a programação é escassa e os espaços não abrem aos finais de semana. $\mathrm{Na}$ ocasião da reabertura houve a retomada de atividades de grupos locais, que em sua maioria participou de atividades no período da ocupação e que foram prejudicados de forma significativa por conta do fechamento das bibliotecas.

A aprovação recente da Lei Castilho ${ }^{6}$ a nível nacional representa um avanço dado às condições do segmento, mas a esfera legal não é o suficiente para garantir mudanças. No caso brasileiro é prerrogativa que políticas de governo sejam tomadas como políticas de estado, talvez assim as Bibliotecas Parque recuperem sua importância e retomem sua função social enquanto centros culturais localizados em territórios populares.

\section{Referências}

Bibliotecas Parque. Disponível em:

http://www.bibliotecasparque.rj.gov.br/bibliotecas/conceito-parque. Acesso em: 15 julho 2018.

IBGE. Censo Demográfico 2010. Disponível em: http://www.censo2010.ibge.gov.br.Acesso em: 05 julho 2018.

Portal do Ministério da Cultura 2018. Disponível em: goo.gl/TF51cB.Acesso em: 13 julho 2018.

Secretaria Municipal de Cultura. Disponível em: http://www.rio.rj.gov.br/web/smc/bibliotecas. Acesso em: 05 julho 2018.

UPP RJ. Disponível em: http://www.upprj.com/index.php/informacao/informacaoselecionado/upp-manguinhos/Manguinhos.Acesso em: 15 julho 2018.

\footnotetext{
${ }^{6}$ A "Lei Castilho" sancionada em 12 de julho de 2018 institui a Política Nacional de Leitura e Escrita (PNLE), como estratégia de promoção do livro, da leitura, da escrita, da literatura e das bibliotecas de acesso público no Brasil
} 